\title{
Correction: Tumor grafts derived from patients with head and neck squamous carcinoma authentically maintain the molecular and Histologic characteristics of human cancers
}

\author{
Shaohua Peng ${ }^{1 *}$, Chad J Creighton ${ }^{2,6,7}$, Yiqun Zhang ${ }^{2}$, Banibrata Sen ${ }^{1}$, Tuhina Mazumdar ${ }^{1}$, Jeffery N Myers ${ }^{3,8}$, \\ Stephen Y Lai ${ }^{3}$, Adrian Woolfson ${ }^{5}$, Matthew V Lorenzi ${ }^{5}$, Diana Bell ${ }^{4}$, Michelle D Williams ${ }^{4}$ and Faye M Johnson ${ }^{1,8}$
}

\section{Correction}

We inadvertently failed to include the complete list of all coauthors for this work [1]. The full list of authors has now been added and the Authors' contributions and Competing interests section modified.

\section{Competing interests}

AW is an employee of Bristol-Myers Squibb which produces dasatinib and BMS911543. The remaining authors declare that they have no competing interests.

\section{Authors' contributions}

FMJ conceived and designed the project, supervised all the experiments, and wrote the manuscript. SP, BS, and TM helped to design and performed all the animal and bench experiments. CJC and YZ performed the gene expression analysis and prepared the corresponding figures. JM, DB, MDW, and SYL assisted with the study design and tissue acquisition, critically reviewed the data, and reviewed the manuscript. Additionally MDW performed all the histologic tissue analyses including interpretation of the IHC and prepared the corresponding figures. AW and ML were involved with the pre-clinical development of BMS-911543 and assisted with the study design and preparation of the manuscript. All authors gave final approval of the manuscript.

\footnotetext{
* Correspondence: speng@mdanderson.org

'Department of Thoracic/Head and Neck Medical Oncology, The University

of Texas MD Anderson Cancer Center, Houston, TX, USA

Full list of author information is available at the end of the article
}

Author details

'Department of Thoracic/Head and Neck Medical Oncology, The University of Texas MD Anderson Cancer Center, Houston, TX, USA. ${ }^{2}$ Dan L. Duncan Cancer Center, Baylor College of Medicine, Houston, TX, USA. ${ }^{3}$ Department of Head and Neck Surgery, The University of Texas MD Anderson Cancer Center, Houston, TX, USA. ${ }^{4}$ Department of Pathology, The University of Texas MD Anderson Cancer Center, Houston, TX, USA. ${ }^{5}$ Discovery Oncology, Bristol-Myers Squibb Company, Houston, TX, USA. ${ }^{6}$ Department of Medicine, Baylor College of Medicine, Houston, TX, USA. ${ }^{7}$ Department of Bioinformatics and Computational Biology, The University of Texas MD Anderson Cancer Center, Houston, TX, USA. ${ }^{8}$ The University of Texas Graduate School of Biomedical Sciences, Houston, TX, USA

Received: 6 March 2014 Accepted: 6 March 2014

Published: 13 March 2014

Reference

1. Peng S, Creighton CJ, Zhang Y, Sen B, Mazumdar T, Myers JN, Woolfson A, Lorenzi MV, Bell D, Williams MD, Johnson FM: Tumor grafts derived from patients with head and neck squamous carcinoma authentically maintain the molecular and histologic characteristics of human cancers. J Transl Med 2013, 11:198.

\section{doi:10.1186/1479-5876-12-67}

Cite this article as: Peng et al:: Correction: Tumor grafts derived from patients with head and neck squamous carcinoma authentically maintain the molecular and Histologic characteristics of human cancers. Journal of Translational Medicine 2014 12:67

\section{Submit your next manuscript to BioMed Central and take full advantage of:}

- Convenient online submission

- Thorough peer review

- No space constraints or color figure charges

- Immediate publication on acceptance

- Inclusion in PubMed, CAS, Scopus and Google Scholar

- Research which is freely available for redistribution 